\title{
Rediscovering a Forgotten City: The Case Study of
}

\section{Laranjeiras}

\author{
Adriana Dantas Nogueira and Eder Donizeti da Silva \\ Department of Architecture, Arts and Design, Federal University of Sergipe, Aracaju 49025-100, Sergipe, Brazil
}

\begin{abstract}
The term "forgotten city” was mentioned by researchers to denominate some colonial Brazilian settlements and cities which seem to have the same characteristics that demonstrate they were hidden along the years and that have the same atmosphere as they used to in their past life, i.e., they have the same traditional type of urban configuration produced at the origin of the city. This paper brings into discussion this character of this city, using as an example the city of Laranjeiras, one of the oldest cities of the State of Sergipe, which had a great and rich trade of sugar, besides significant cultural and political activities, being known as "Brazilian Athens" in the 19th century. Then, Laranjeiras decayed and stopped growing along the 20th century. However, it has had a good perspective to develop again with insertion of new different activities recently. The initial Portuguese planning to villages in Brazil followed specific rules and had a systematic assistance, what discards the myth that many Brazilian cities were born and grown up as a spontaneous form without planning. Studying some factors deeply, as spatial configuration, settlement localization and urban grid, it can be possible to point some recognizable elements which demonstrate that some cities were built to be forgotten. The methodology used for the analysis of Laranjeiras presents many historic, economic and cultural aspects related to the spatial-syntactic studies (Space Syntax Theory), bringing to light some interesting thoughts about urban form and social life.
\end{abstract}

Key words: Urban form, space syntax, urban configuration.

\section{Introduction}

Some Brazilian cities were established, especially in the ages 16 to 19 between sea and river, and ended up being a sort of connection between the interior and other coastal cities, e.g., Penedo (in Alagoas), São Cristóvão and Laranjeiras, in Sergipe. Such cities have been called by some researchers "forgotten cities".

These cities are rarely mentioned on national or international researches, sometimes cited because of one or another residential, military or religious building of architectural importance [1].

San Cristóvão, a town established by the Portuguese in the 16th century (origin in 1590), was studied by this point of view by Nogueria and Donizeti da Silva [2], which wove some intriguing questions: "Why this important historic city is not recognized as one example of Urbanistic Portuguese Universe like many

Corresponding author: Adriana Dantas Nogueira, PhD, professor, research fields: urban morphology, urban history, urban development. E-mail: adnogueira@gmail.com. other cities with the same pattern and typology? Are there forgotten cities in other countries, except in Brazil? Then, what are the characteristics of them to be compared one to another?”

The main question to be tried for an initial exercise of reflection was: "Were these forgotten cities created to be forgotten?”

However, it is necessary to define what a forgotten city and its main characteristics is. Thus, this article attempts to understand how the urbanization of the city of Laranjeiras was from the name of "forgotten city" attributed to São Cristóvão, both located in the State of Sergipe and thus further the study based on its urban traits, emphasizing the socio-economic and spatial-syntactic aspects in order to bring to light some considerations on the study of urban form and social life over the centuries and checking, this way, if Laranjeiras is also part of the list of the "forgotten cities”. 


\section{Forgotten City as a Possible Portuguese Urban Standard: The Example of São Cristóvão, Sergipe}

The first defining feature of a forgotten city may be its location between the coast and the countryside. In determining the location of a city, there are many social political and religious variables [3-7]. But what the Portuguese troops were searching for in the outskirts of São Cristóvão when it was founded?

"A letter wrote by a Brazilian governor named D. Luis de Souza sent to King Felipe II, which traveled to Itabaiana Hill, to testify what Belchior Dias Moréia said about the existence of precious metal, as silver, over there in 1619 [8].”

The Portuguese troops had its defense and attack strategy, especially by the small contingent of soldiers to large areas of land. His profound knowledge in geography and geometry [9] prove that the choice was based on areas that could be favorable to the defense, in other words, they were seeking land where they could see the enemy without being seen. Therefore, the defense points of the coastline were not revealed since they would be the last places of refuge in case of attack by French or Dutch troops. Therefore, these cities would be strategically located, in other words, a little more hidden (if considered the direction of the countryside) [10].

Portuguese planning for colonial towns in Brazil follows specific rules [9], and denies the myth that the Brazilian cities grew spontaneously and with organic standard in the colonial period, since the Portuguese established a legislation to explore areas of gold, including appointment of Portuguese employees (receiving some part of the gold explored, avoiding the sale of gold to foreign groups), besides establishing a law to deal with the "bandeirantes" (pioneers), who claimed to own the land already in the 17th century, and also established small farms to Portuguese men, as well as advanced on the Spanish towns (before the Treaty of Tordesillas) to effect the Portuguese occupation in these areas, leading to the international rule of "uti possi de tis", which says that the property could be claimed by those who lived in it.

The location of São Cristóvão, among hills, near the Vaza Barris River, and the São Francisco River separating the towns to the north (where battles occurred more frequently), hindered the arrival of the battles news . Around 1608, there were 500 buildings, a square with a church, eight sugar mills [11], which made the city a place of relaxation and advantage against enemies (Fig. 1). São Cristóvão is a hill town and a city that has a natural pier along the Vaza Barris River, which can be regarded as similar to other "not forgotten" coastal cities in Brazil, yet there are differences.

When comparing São Cristóvão to some Brazilian cities like Belém (Pará, Brazil), a coastal city, and Ouro Preto (Minas Gerais, Brazil), a mining town [2], three major sources of analysis can be mentioned: the image of the city, the urban network of roads and streets (the urban grid), the location of important buildings in the urban setting at that time.

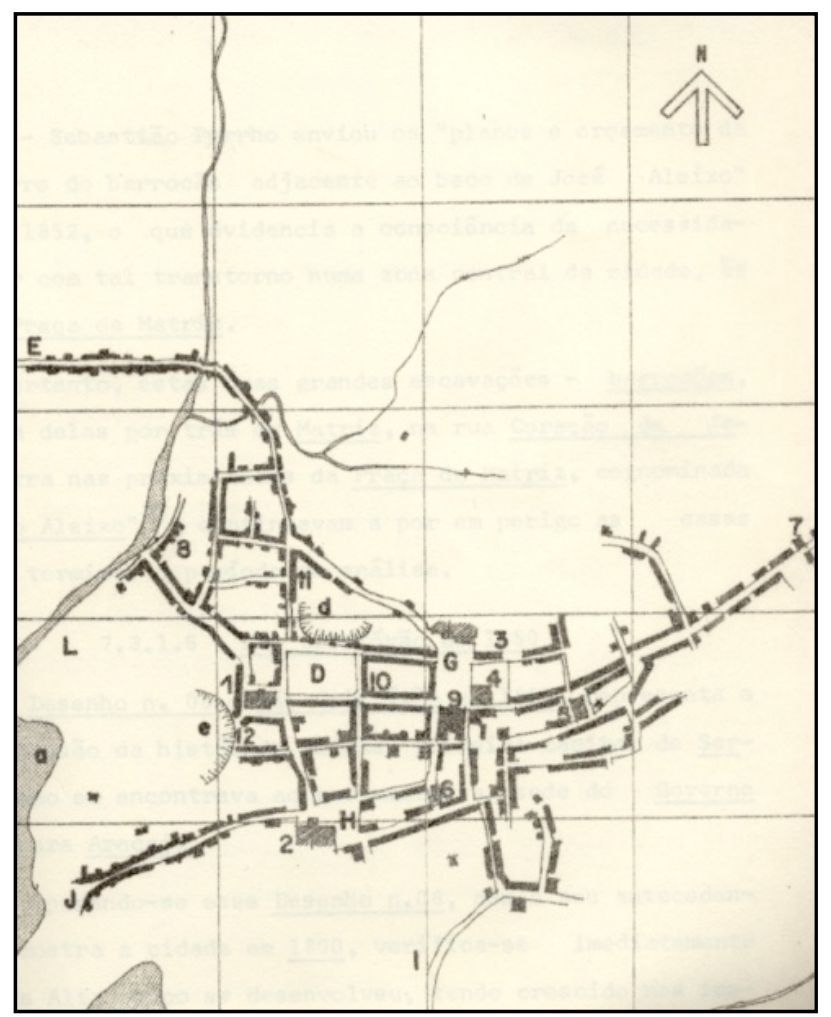

Fig. 1 São Cristóvão map in 1850 [12]. 
São Cristóvão had a very compact configuration while it was growing, different from, for example, the city of Belem developed in two opposite directions s in a sparse way and Ouro Preto along the River.

Another difference is that São Cristóvão seems to have been a city which followed artistic principles in its implementation [13] which means that it has always had an important building at the end of its streets, what seems that the pedestrian flows were in circles, going through buildings with the most important uses and activities such as churches, administrative buildings, etc.. Belém is a city that presents an urban sprawling and Ouro Preto seems to be a mixture of both.

São Cristóvão was originated at the top of a hill, which reveals areas of concern with the defense strategy of the city, but maintains its proximity to the river and the sea (but not limited to the sea), Ouro Preto is limited to the river, besides being over the hills and Belém borders on to the sea, representing the constant invasions by land area at that time.

It can be noticed that all these three cities have deployment characteristics in common, which relate to both external factors coming from the water (either river or sea), as much as they have concerns about the social and commercial life such as housing and work, but an urban configuration, with rather specific characteristics and that differ from one another.

However, what makes São Cristóvão a "forgotten city” and the others not? Especially, we can consider their urban form as one of the major features, which directs the flow to the internal areas of the city, creating a "moviment around", unlike the "movement to" in which one can find long paths that direct growth to certain areas of the city, as "urban tentacles" or "structuring path of growth", a not-existing condition in São Cristóvão.

The intention here is not to exalt the morphological determinism since it is known that other factors may have contributed to the urban formation of this town such as economics and politics ones (whether local or national ones). The fact is that the city remained with the same urban atmosphere from its origin for many centuries. Importantly, these factors should be analyzed as well, so it is believed that this paper might be a starting point for further research and reflection.

Nowadays, São Cristóvão has 78,800 inhabitants (data from IBGE (Brazilian Institute of Geography and Statistics) in 2010). Many residential settlements were located nearest to Aracaju by the government, but being in São Cristóvão limits. Then, its population is more connected to Aracaju, regarding to the economy and services, which can be a factor of undevelopment of its main urban core, being its town as a forgotten city, along the decades.

The map of the State of Sergipe brings the location of cities in this territory in which the urban grid of The Great Aracaju can be highlighted (Fig. 2) as well as you can see the lack of continuity relation between the headquarter and housing subdivisions that are in the city of São Cristóvão.

After some considerations on the urban form of São Cristóvão, while forgotten city, it can be checked as if the same happens to the Laranjeiras city, and for that it must provide the location and configuration of the city. A deeper analysis of its urban form will be held from the Space Syntax theory (created in the 80s by a team of professors from Bartlett School of Architecture of the University College London) [14, 15].

\section{Laranjeiras: Its Urban History and Morphology}

The location of the Laranjeiras city, despite being in the interior, has a strong identity with the Cotinguiba River, which crosses the city, but has no direct relation to the sea, like the city São Cristóvão previously presented, which also has a strong relation to the Vaza-Barris River (Fig. 2) [17].

According to data from the Urban Plan of Laranjeiras in 1975, which the executing team said, there is no city plan or cartographic support previous to that time. In 1934, the Hall City hired the engineer José Valente Monteiro to carry on the city plan. In 1938, in 


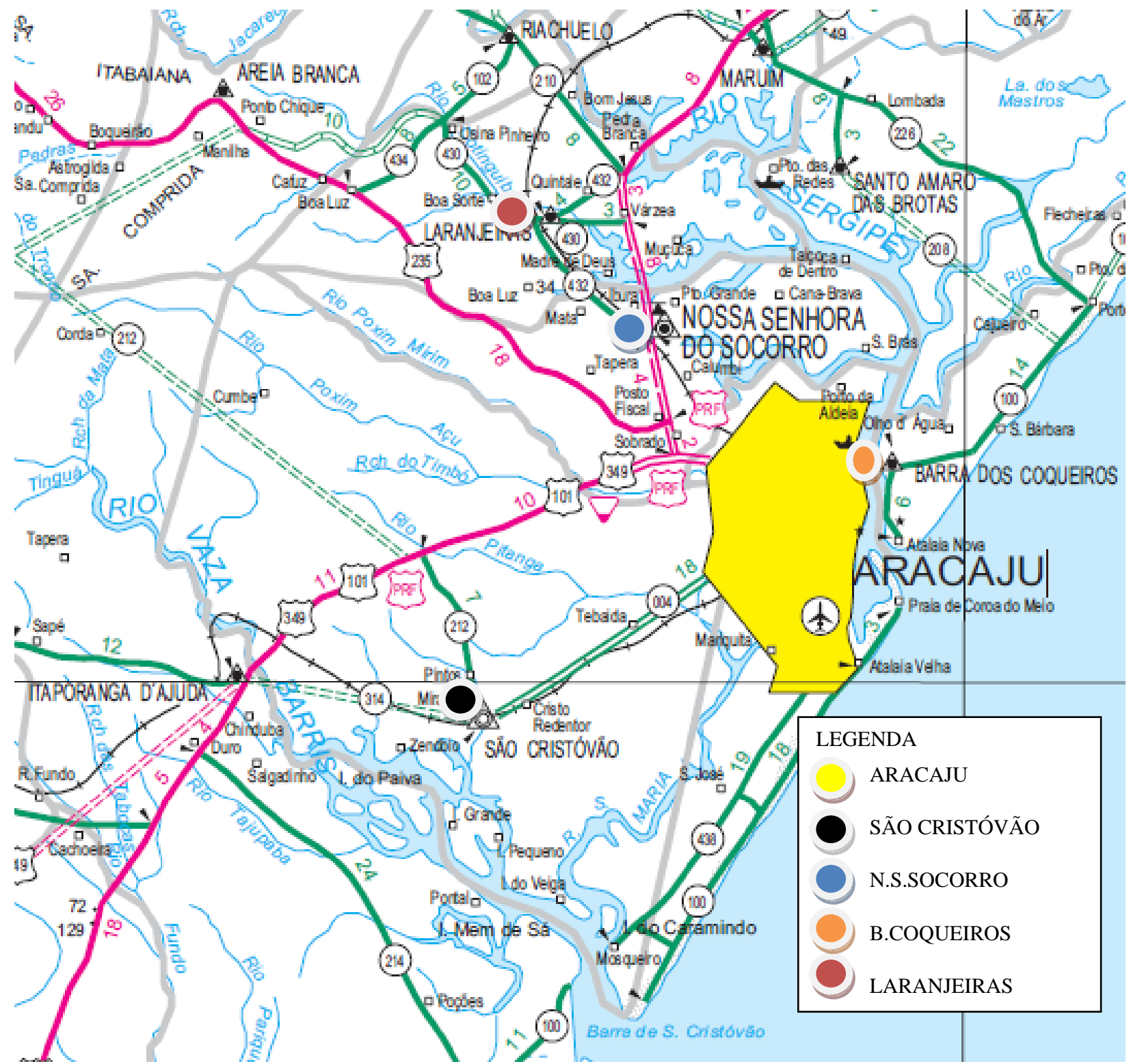

Fig. 2 Map of municipalities of Sergipe emphasis on São Cristóvão, Aracaju, Nossa Senhora do Socorro, Barra dos coqueiros (“The Great Aracaju”) and Laranjeiras [16].

compliance with Decree-Law 311 of March 2, the City Map would contain plants of the districts and the main core, with delimitation of the urban and suburban areas, yet none of these documents has been found or given to this team. Thus it became evident that the streets are aligned by following the river route, being "the historic center installed on a meander terrace of Cotinguiba, partially occupying the larger bed of that river" [18].

Around the year 1800, the settlement of Laranjeiras had nearly 3,000 people and in their port (known as Barra de Cotinguiba) used to anchor twenty boats and, during summer (September to March), each one of them used to travel four times to Salvador, Capital of Bahia. There were 20 factories to grind sugar cane, sugar mills and distilleries. Across the entire region, there were 7,000 people who were employed in the farming of manioc, beans and sugar cane. Until then, uncertainty reigned in the village, lack of administrative and institutional infrastructure would still delay the rise of settlement to village for three decades, as shown in Fig. 3 [18]. 


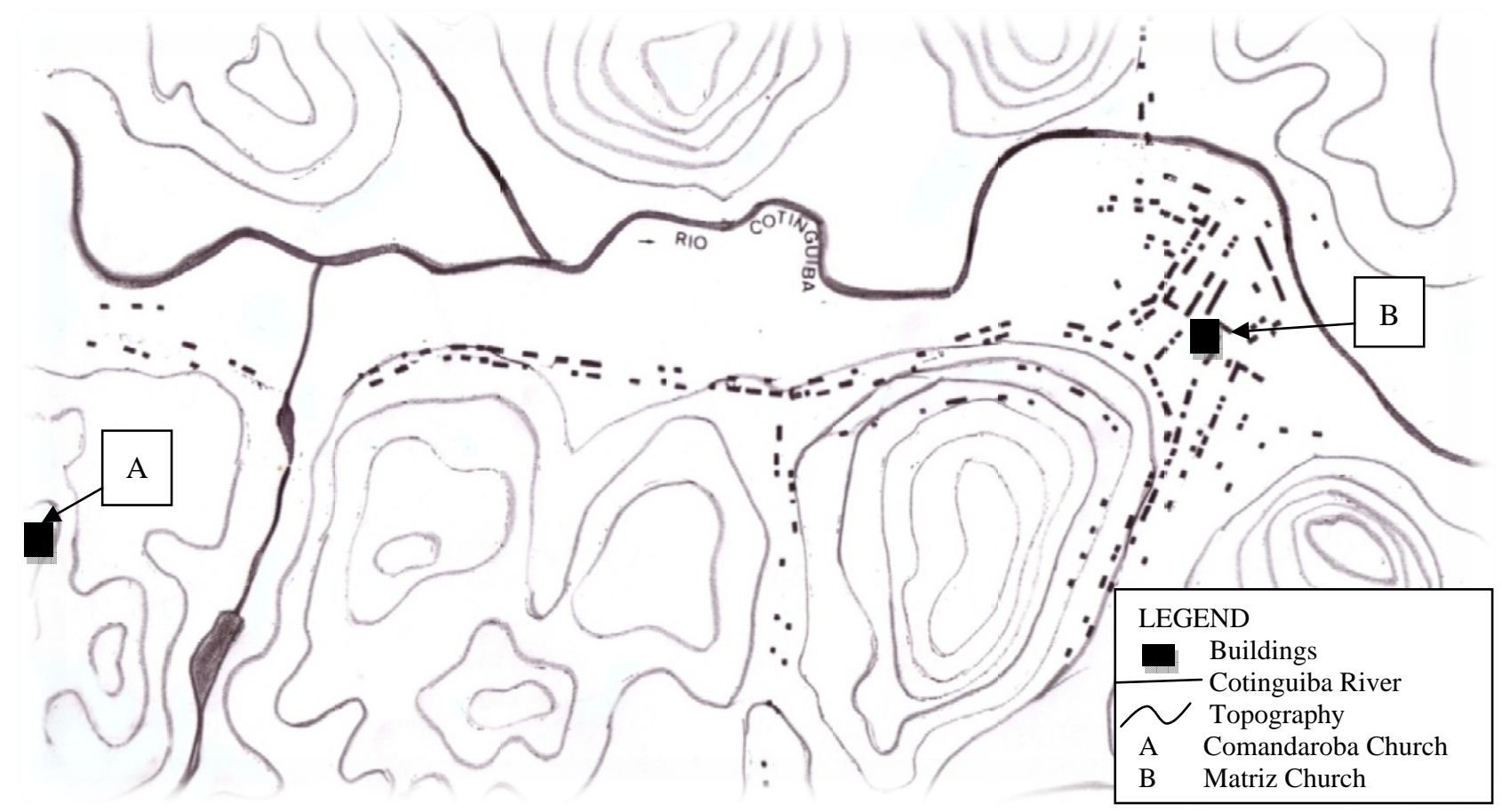

Fig. 3 Laranjeiras and its initial settlement in 1840 [18].

The 19th century was the golden century for the city [2], Laranjeiras was already considered the richest settlement of the province in 1824, with over 60 sugar mills, brandy and cigar factories, besides depictions of European trade houses, and then it became a "city" on May 4, 1848. In the late 19th and early 20th century, theaters, colleges and clubs, increasing the city's intellectual life, were founded. The hillsides were being occupied by buildings in its lower part, while the upper part was where the churches were located (Comandaroba, Bonfim, Bom Jesus dos Navegantes, Misericórdia and Chapel Sant'Aninha). The port, between September and March, housed the ships that brought the goods and took the sugar to other regions. In a certain way, it was a storehouse city [18]. There was a growing population, which provided relevance to the business functions.

However, with the abolition of slavery on the country, the landowners could not pay workers, much land was abandoned, and grass was planted instead of the cane, the land turned into pasture for cattle. There was a rapid decay of Laranjeiras during a period of just 10 years, then in 1897, according to Ref. [18], “... the mercantile life is found in complete decay”, attributing this to the development of nearby cities Maruim and Riachuelo and mainly to its proximity to Aracaju (which became the capital in 1855, about $20 \mathrm{~km}$ distant).

An interesting fact to be presented is the resolution to build a market in 1883, which was initiated only in 1893, covered in 1901 and its construction dragged on for 32 years, getting ready only in 1925, as the last great work of Laranjeiras [18]. The 20th century is marked by a kind of "forgetting " of the city when it comes to urban development and a daily exodus of the population that will work in Aracaju comes up, and returns to the end of daily shift, thus protecting the name of a dormitory town. In 1970, the city had a population of about 4500 inhabitants, which was over 9,000 in 1887. Laranjeiras City was recognized as City Monument by the state government in 1971 [19].

Within the recent overview of the city [20], one can mention three industrial-sized units: "The Pinheiro Sugar Mill, of sugar cane processing”, the cement factory Poti, the fertilizer industry FAFEN, besides a 
distributor of Petrobrás and another one of White Martins.

"As for the skilled labor force, it comes from Aracaju and other municipalities. Public transport is limited to the connection between the municipal headquarters and Aracaju. There are no regular lines of passenger transportation services between headquarters and the settlements, the population commutes from the settlements to the headquarters on foot, by bicycle or irregularly in school bus transportation.” Thus, the roads have a very important role in the flow of people and cargo, mostly paved, although in very poor maintenance.

Laranjeiras presents, as an urban area, the headquarters (main core) and ten more settlements, often located along the highways, there is no support for the movement of vehicles and cargo carriers either, which generates traffic disturbances, mainly in the BR-101 (Fig. 4). Still, according to Ref. [20]:

"The Historic Center is the urban area with more paved roads. In the neighborhoods, the streets are not paved and in the settlements, the streets are the highways, except in the settlement of Pedra Branca, which already has roads regardless the highway."

The city of Laranjeiras, in its economic aspect, has a strong dependence on Aracaju, especially in trade; there is only a basic trade in small establishments and services. As for the tourism in the city, it does not cause a significant impact on the local economy, nor does the population have lots of courses to train specialists for the public attendance, or to work in local industries. The majority of the population works in the monoculture of sugar cane and pastures, and the public administration ends up as the major generator of jobs, where, for example, the City Hall had revenue, in 2004, coming from state and federal government programs of $80 \%$ ) [21].

With the implementation of a federal campus in 2009, in the historic area of the city, which has approximately 23,000 inhabitants (data from IBGE (Brazilian Institute of Geography and Statistics) in 2010) starts hosting a floating population of more than 800 people a day, including students, teachers and technicians , causing impacts in different aspects, such as accessibility, traffic, housing, inter-relationships between the academic community and the local community, use and appropriation of places, change the urban landscape in the central area (which was listed at the National Preservation List by IPHAN since 1996) among others.

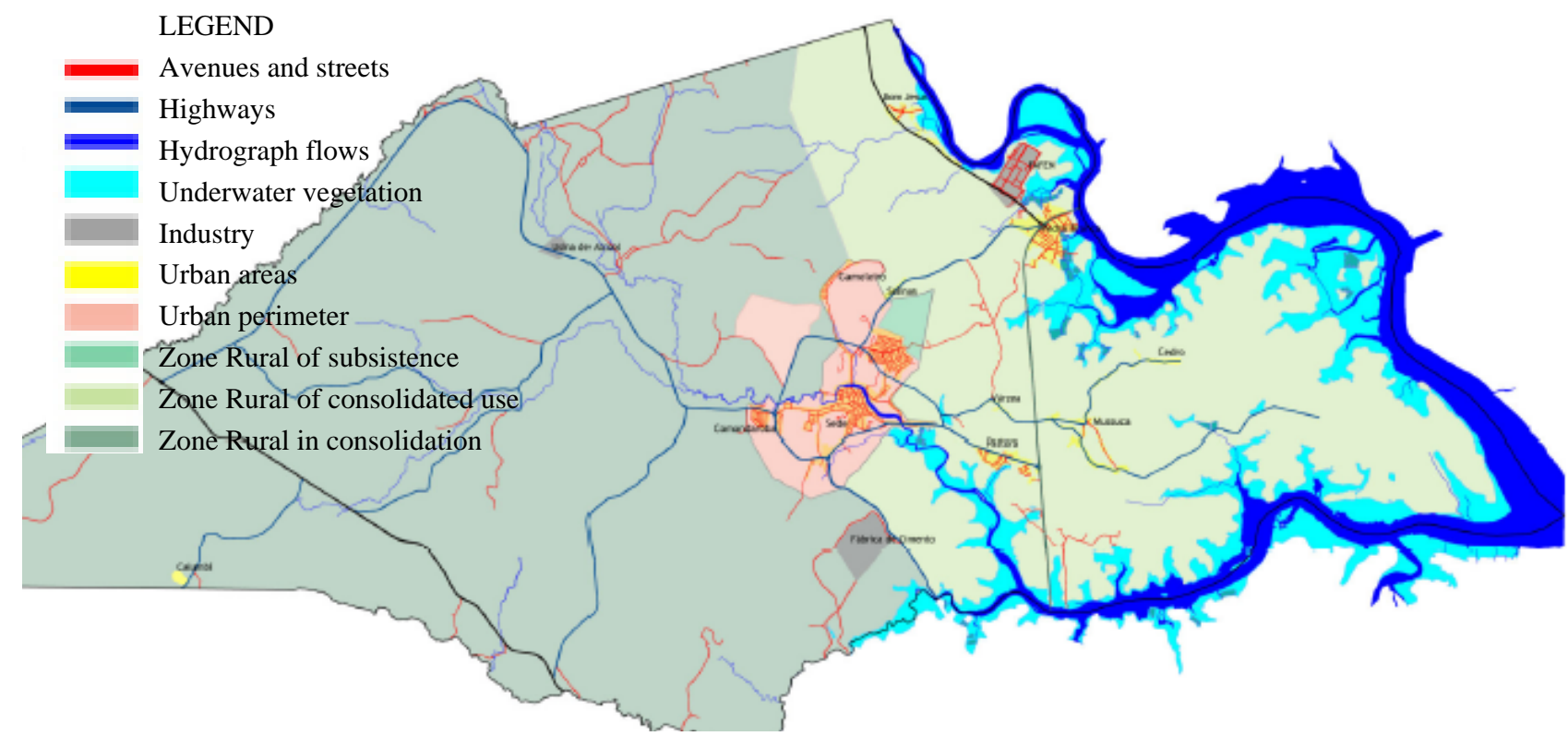

Fig. 4 Town of Laranjeiras (urban core and settlements, with delimitation by the Cotinguiba river to the east side) [21]. 


\section{Spatial Syntactic Analysis of Laranjeiras}

The space syntax begins its analysis from the transformation of the urban grid in axial lines, in other words, an urban map is called axial map, in which all roads are transformed into lines that connect to each other from the crossing of the pathways.

When analyzing a city under the aspect of the theory and methodology of the space syntax, it is necessary to understand the conception of the analysis that is based on three premises, which are important to describe it in order to understand how the urban morphology of Laranjeiras is, by checking its properties and being able to conclude whether these resulting characteristics may be characteristic of a "forgotten city".

The first premise is called Natural Movement, which explains how urban configuration influences the movement, in which the proportion of movement in space is more to the configuration of the urban system (grid) than for the factors of attraction (attractors). Built environment influences their attractiveness, but does not receive the same influence, as well as the setting influences in movement but the movement does not change it, while the attractiveness and the movement are inter-relate intimately [22]. According to the space syntax, one must first understand the operation of the spatial configuration, to then be possible to understand how the movements and attractiveness behave. Thus, "natural movement” was the term suggested to express the movement determined by the spatial configuration.

The second premise is called "city as a moving economy". It basically proposes that the differences in production of the movement caused by the urban design have a bounce in the effect of land use. The key to understanding how the city and function of human existence in the cities is to understand how people organize the space in a particular setting, which derives from the fundamental proposition of the second assumption, suggesting that socioeconomic forces shape the city primarily through the relations between movement and structure of the urban layout [15]. Trade in stores, for example, may be one of the main attractors of the movement. This attraction exerted by the activities actually occurs, although one must ask why they are where they are. The presence of shops can attract people, but they do not change the value of integration of a road, as this is a purely spatial measure derived from the position of this line in the urban area. The relation between the structure of urban design and the movement should not be explained by pointing the shops, but to explain the location of the stores by showing the relationship between urban area and the movement. Certainly, some places in the urban structure have a greater potential to favor the flows than others, because they have more interstitial spaces (beyond spaces) and it will depend on the configuration of urban space. These sites tend to have high densities, which, in turn, can attract new buildings and uses will emerge to take advantage of this, which is the so-called multiplier effect (originally generated by the relationship between spatial configuration and movement).

The third premise is called "centrality as a process" and proposes that local integration centers promote a process of centralization, so that the conditions of urban design are priorities, and as this process of centrality intensifies itself, it also causes a return to the urban layout, which has its structure changed. The result of researches show that the formation of convex living center appears to be governed by the scale; only the larger center is strong enough, weaker centers (sub-centers) tend to remain more linear. In any case, the conditions of the urban area are critical, initially with integrated location, providing the accessible areas, and then providing the logic of the growth of living center, in a linear way to the convex shape. There are two movements that generate centrality: the “movement to" essentially one-dimensional movement known as origin-destination, and the "movement around" within a local area, relate all the sources to all destinations within that area, which is essentially 
two-dimensional convex in shape, and generates "quasi grids", almost orthogonal forms of outline. This second process is effective to optimize the integration measure, which minimizes the length of all trips to other points within a two-dimensional area. That's what usually happens in the urban center (historical or commercial), but can also occur outside it, generating a sub-centrality.

From the computer program called AXMAN, one can check that the levels of some urban properties in an objective way, through quantitative data and not only subjective, for example, can obtain values for the integration of a particular urban area or city. Reflections on the urban form established in the city of Laranjeiras can be considered integrated or fragmented, and this feature facilitates the designation of "forgotten city". After the transformation of the recent urban map of Laranjeiras (2008) in axial map, in other words, the paths become axial lines, always connected to each other within the whole urban system, so that the lines covering the urban layout of the city at its maximum extension length. The axial map is then rotated in AXMAN program, which provides the map of Global Integration, which presents, through colors, its maximum and minimum integration (red and blue colors, respectively) as well as other important measures for more objective analysis as the connectivity map, control map, depth map, local integration map, etc..

In this paper, the global integration map (of the entire urban system) can be explored to the detriment of others previously cited, because it enables you to analyze the movement and flows more broadly, which is what we try to check the relations between parts of the city (main core of Laranjeiras and its settlements), defining which types of motion due to the third premise can be verified and how they can represent a feature for a "forgotten city".

The city of Laranjeiras, as already mentioned, has many settlements due to its initial origin in different times, and their locations are also due to as much as the search for areas that are less rugged, as, historically, are located where the old mills and farms were.

Laranjeiras presents a striking feature which is its proximity to the highway BR-101, which makes this the only way to function as an arterial via in the city. Some local highways/roads can be considered very significant, since in these highways/roads, transit both goods and the general population to be one of alternative paths between Laranjeiras and Aracaju, the state capital, as well as provide access to workers in cement factories, one of them is known as Industrial Highway, the others are the SE-245 and part of the SE-429. Major access roads to the city are among the so-called "collector roads", such as the Valter Franco highway, the main access (entrance) to the city by BR-101, and like SE-429, being the interconnection of the municipal main urban core (historic center) to the settlement Pedra Branca, located near one of the factories. The other roads are considered as local roads, which means that seat in the in the urban center there is not a specific hierarchy in the road system, as for example, a distinction between streets and avenues (Fig. 5).

The configuration of the urban area of Laranjeiras map is transformed into axial map, considering the BR-101 highways and local roads, which are the pathways that connect the main core of the city to the other settlements and cities in the surroundings, as N.S.Socorro and Aracaju.

The next step is to check the program AXMAN which the maximum and minimum values of the property claimed Global Integration. As it can be seen on the map of Global Integration, the highest values are exactly in the BR-101, which indicates the greatest potential flow of the area. This is consistent with the specificity of the road of transport and cargo (Fig. 6).

The configuration of the city can be regarded as highly fragmented, being the BR-101 few links to the roads that enter the municipal headquarter, which seems to create barriers to the development of the intraurban movement and emphasizes the "movement to" taking the flow to pass to the edge of the town and 


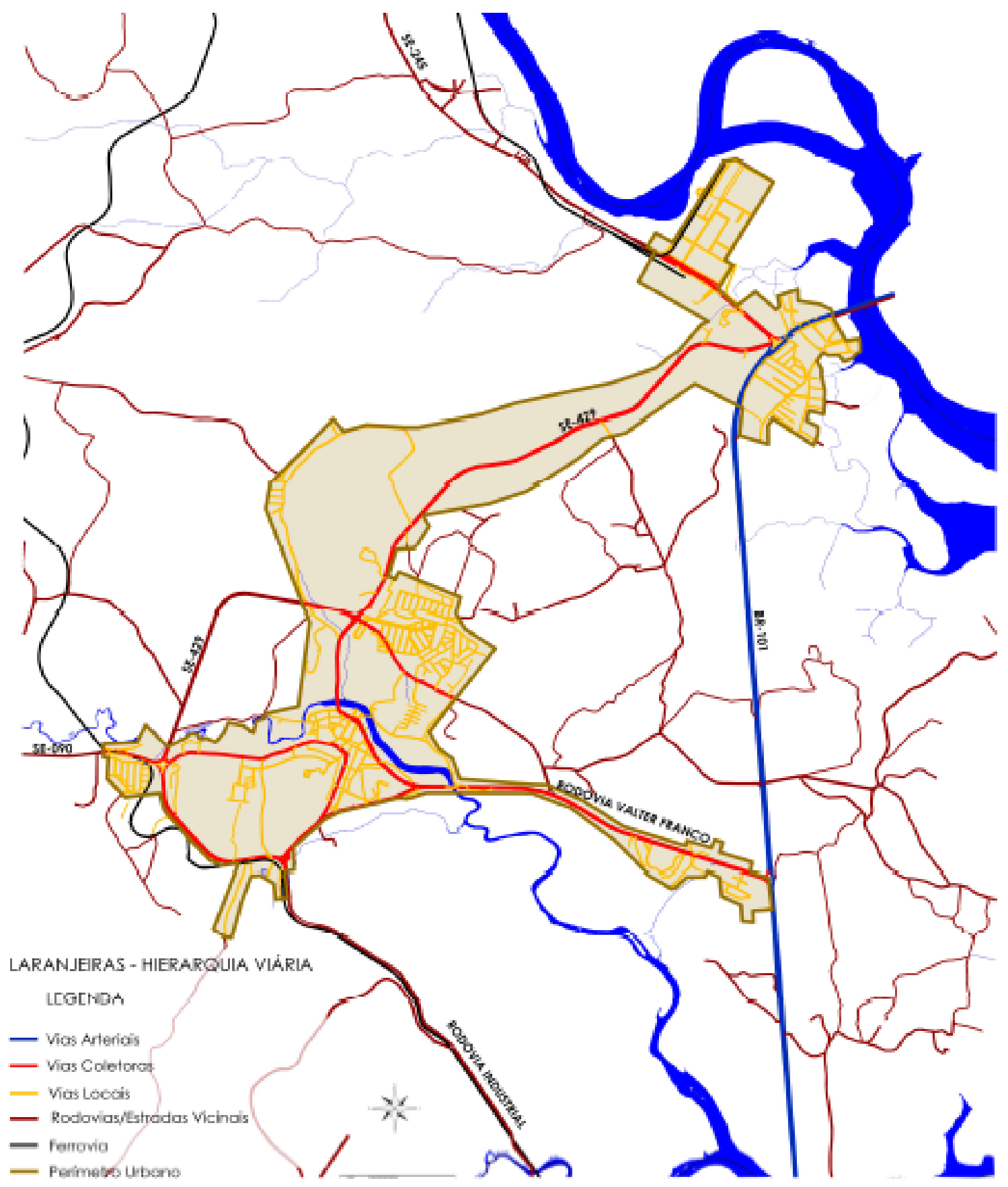

Fig. 5 Map of hierarchy of the road system in the town of Laranjeiras [20].

not going into it. Not even the main access to the city has a configuration that has a potential to create centralities or subcentralities areas (the third premise).

This same access route to the city (Valter Franco Road or SE-090) could be analyzed by what the Space Syntax Theory called "city as movement economy" (the second premise), or it could serve as an interstitial space between the BR-101, which has the highest value of global integration, and the urban center (main core), now with the lowest values, this route has an enormous potential to favoring the encounters (flows), but this can be optimized from investments in terms of insertion of infrastructure and roads. 


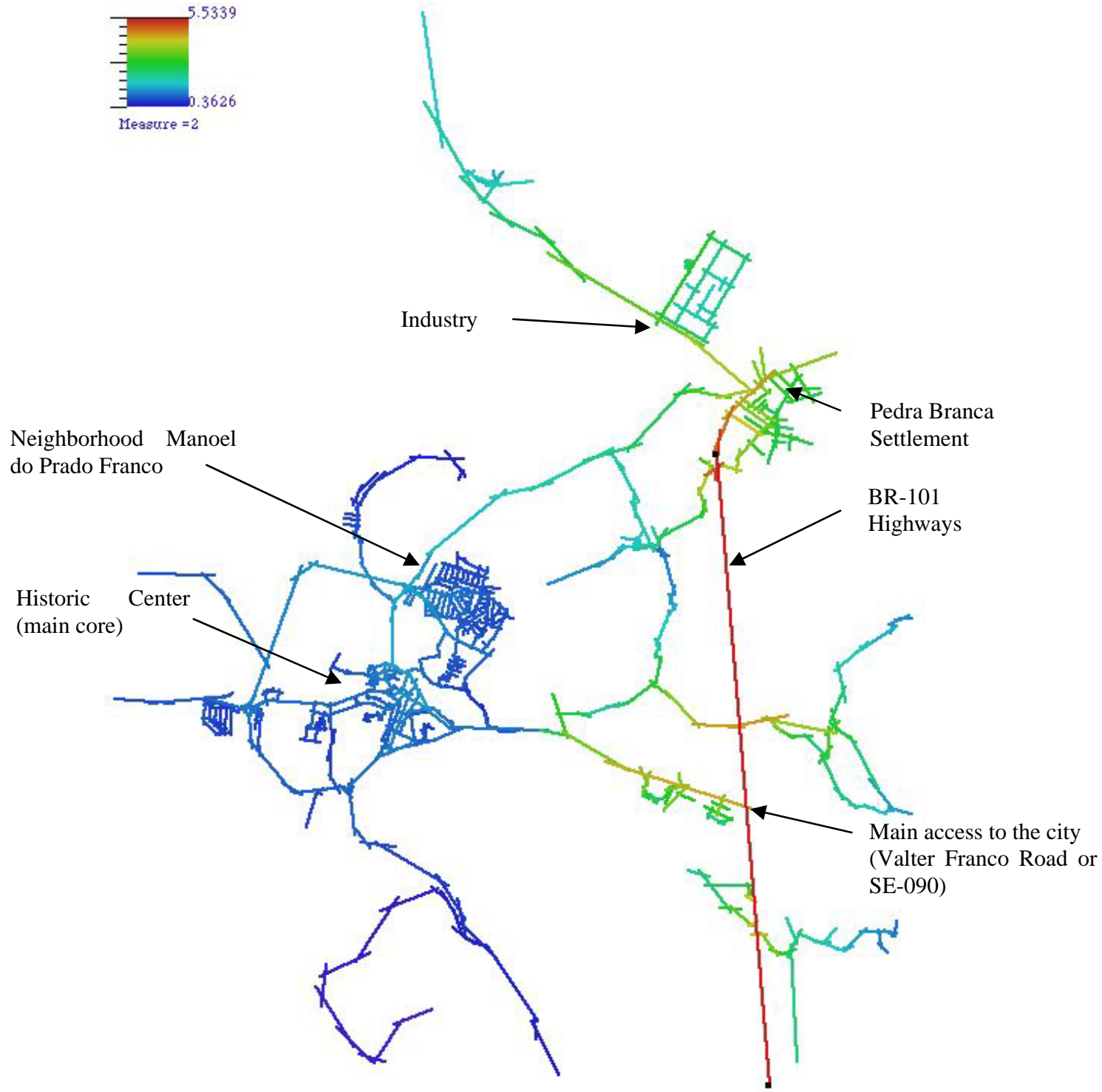

Fig. 6 Global integration map of the Macrozoning of the Municipality of Laranjeiras (historic center and settlements), 2011. Source: from the authors (utilizing computer program called AXMAN, by Space Syntax Laboratory, University College London).

It is possible to say that there is a tendency to sparseness and consequently the formation of fragmented areas of the general context of Laranjeiras, revealing a strong and significant discontinuity in the road area and not easily accessible spaces, in other words, there is not a compactness in the urban area of Laranjeiras due to the proper configuration of the road system to scattered settlements, without having an urban form that favors the orthogonality, which could facilitate a more accessible layout and the creation of internal motions (kind of "movement around"), which could boost the local flows.

\section{Final Considerations}

From the study of the spatial configuration, location of urban settlements, the urban layout, the story of an urban city, it may be possible to identify some recognizable elements that can show that some cities were built to be and remain "forgotten". You can name a few of these points in the case of Laranjeiras:

(1) The initial location of the settlement does not seem to demonstrate ease of access by land, as much as through land, to be implemented between mountains and hills, away from the sea, and being the river that 
borders the city very curvilinear, hindered the movement of boats, besides the time rainfall between March and September, when it was impractical to navigation;

(2) The urban configuration analyzed, since its initial period, did not present itself with a compact urban form, which could generate a flow or movement that favored collective activities, in other words, the urban form has always showed itself highly fragmented, even today, when it was analyzed from the Space Syntax theory, being considered the urban center and its settlements, as well as the access link between the main core and the BR-101, which is the route with the highest value of global integration that has not been optimized, historically, in the view of the integration of local urban facilities (infrastructure and services);

(3) In addition to spatial factors of urban form, the history of Brazil and the city eventually conform more to the vocation of Laranjeiras as a "forgotten city", such as the proximity to the state capital and the decline of the sugar ended up emptying Laranjeiras along the 20 century, transforming it into a dormitory town, even after being considered the richest city in the State in the previous century;

(4) Also, today, there is great difficulty in mobility to the main core of the city, both in the provision of public transport (service) and the configuration of the urban layout (accessibility), which does not show structural ways of more intense traffic, in other words, long routes that can be structuring the growth of the city or that more easily interconnect it with other major urban centers such as Aracaju.

A great similarity between São Cristóvão (the first city to be recognized as "forgotten city") and Laranjeiras was the characteristic of the initial implantation of São Cristóvão be characterized as a compact way, while the one from the Laranjeiras is also born in a compact form by 1800 in the surroundings of the Matriz Church, although, already in 1840, presents itself as the model of Ouro Preto city, growing along the banks of a river, the Cotinguiba, from a linear growth, this can be explained mainly by the very uneven topography, including hills, in which the religious buildings were located.

São Cristóvão and Laranjeiras have factors that can be considered common to both, especially regarding to the growth of urban form, which, its origin being compact or linear, currently present highly fragmented, with large areas of scattered settlements or villages in the municipality and with poor accessibility, in which there are no strong centralities or sub centralities.

As one can cite the location of the two cities, relatively distant from the sea and river banks, but with some discretion towards travelers and strangers, besides historical factors that made them move from a certain height and wealth to socio-economic stagnation, Laranjeiras, with its sugar period and the capital of São Cristóvão as the capital of the State of Sergipe.

It is hoped that this paper can have a split for further research and reflection on what other features could conform a "forgotten city”.

\section{Acknowledgment}

This article is one of the results of the study "Neighborhood Impact: the city of Laranjeiras" developed at the Federal University of Sergipe and coordinated by the authors, with the participation of scholars and PICVOL PIBIC-CNPq-UFS, Henrique Magno Nascimento Belém and Jéssica Maressa Rodrigues Siqueira. It is from the Course of Architecture and Urbanism, having the support of FAPITEC-SE.

\section{Reference}

[1] P. Tirapeli and W. Pfeiffer, The Most Beautiful Churches of Brazil, Metalivros, São Paulo, 1999. (in Portuguese)

[2] A. D. Nogueira and E. Donizeti da Silva, Forgotten cities: São Cristóvão in Sergipe Del Rey, in: Proceedings of ISUF (International Seminar on Urban Form), Ouro Preto, 2007. (in Portuguese)

[3] C. Furtado, Initial Economic Organization of Brazil, Fundo de Cultura, São Paulo, 1961. (in Portuguese)

[4] C. Prado Junior, Economic History of Brazil (42nd ed.), Brasiliense, São Paulo, 1994. (in Portuguese) 
[5] A. M. M. Belluzo, Brazil of the Travelers, Metalivros, São Paulo, 1999. (in Portuguese)

[6] N. G. Reis Filho, Evolução Urban Evolution of Brazil (1500/1720), Pioneira, São Paulo, 1968. (in Portuguese)

[7] N. G. Reis Filho, Towns and cities images of Colonial Brazil, Edusp, São Paulo 2001. (in Portuguese)

[8] L. S. Santos and M. T. Nunes, Catalogue of Manuscripts Documents of the Captaincy of Sergipe (1619-1822), UFS/Departament of History, Aracaju, 1999. (in Portuguese)

[9] R. M. Delson, New Towns for Brazil-Colony: Spatial and Social Planning in 18 Century, Alva-ciord (Ed.), Brasília, 1997. (in Portuguese)

[10] M. Valla, Urban Space in Fortified Enclosure in the 17th Century: Theory and Practice, in: International Colloquium in the Urban Portuguese Universe-1415 to 1822, National Commission for the Commemoration of the Portuguese Discoveries, Lisbon, 1998, pp. 383-392. (in Portuguese)

[11] M. T. Nunes, Colonial Sergipe I, Brazilian Time, Rio de Janeiro, 1989. (in Portuguese)

[12] P. O. D. Azevedo (org.), Urbanistic Master Plan of São Cristóvão (Vol. 1-4), Team of Architectural and urban Restoration and Renovation, University of Bahia, Salvador, 1975. (in Portuguese)
[13] C. Sitte, City Planning According to Artistic Principles, Martins Fontes, São Paulo, 1992. (in Portuguese)

[14] B. Hillier and J. Hanson, The Social Logic of Space, Cambridge University Press, Cambridge, 1984.

[15] B. Hillier, Space is the Machine, Cambridge University Press, Cambridge, 1996.

[16] Google Map Website, available online at: http://maps.google.com.br.

[17] F. Freire, History of Sergipe (2nd ed.), Vozes, Petrópolis, 1977. (in Portuguese)

[18] P. O. D. Azevedo (org.), Urbanistic Master Plan of Laranjeiras (Vol. 1), Team of Architectural and urban Restoration and Renovation, University of Bahia, Salvador, 1975. (in Portuguese)

[19] B. Gois, Laranjeiras: between the past and the present, in: A. D. Nogueira and E. Donizeti da Silva (Orgs.), The Awakening of Knowledge on The Bluish Hill (Vol. 2), Edufs, São Cristóvão, 2009, pp. 179-199. (in Portuguese)

[20] Participatory Master Plan of Laranjeiras (Vol. 1), 2008, pp. 22-24. (in Portuguese)

[21] Technical Report for the Elaboration of the Master Plan of the City of Laranjeiras, Vol. 1, May 2008. (in Portuguese)

[22] B. Hillier, Centrality as a process: Accounting for attraction inequalities in deformed grids, Urban Design International 3/4 (2000) 107-127. 